\title{
The best way to predict the future is to invent it
}

\section{Anton V Emmanuel}

The country slumps in the middle of a global depression, with a declining economy associated with rising unemployment rates running at $20 \% .{ }^{1}$ Internationally, the USA looks poised to elect a Democrat for a second term and the world is watchful of expansionist aims in the Oriental East. The year is 1937 and the eastern nation was Japan, and the culmination of all those events was to be the second major international conflict of the 20th century.

If the political world in 2012 is only somewhat different, the medical world is utterly so. The British Society of Gastroenterology (BSG) was formed in 1937, driven by Sir Arthur Hirst, as a club of 39 gentleman members. ${ }^{2}$ It was not until 25 years later that the membership became more scientific than social, with 2 day annual meetings of clinical and academic papers. Membership now stands at 3600 . While still retaining the initial aims of advancing gastroenterology, the Society has come to be a champion of science with a reach to influence health practice and policy in the UK and internationally.

'Gut', the BSG's scientific journal is Europe's highest ranked specialist gastrointestinal journal, and 'Frontline Gastroenterology' is in its infancy as the Society's clinical journal of best practice and service delivery. It is in this role that with great pleasure we present this supplement of the journal to commemorate the 75 th anniversary of the BSG. The aim of the edition is not to hark back to historic aspects of practice, but rather to enthuse in the diversity and quality of modern gastroenterology and hepatology practice. The content reflects the current face of gastrointestinal practice, with pieces reflecting the centrality of the patients', nurses' and trainees' voice. The articles provide a perspective of what is thought will happen in the field in the next decade, both what is in the pipeline (either just ready for implementation or already in the practice of the early adopters), and what is more speculative but with serious undertones- something to make us think.

The title of this piece is a quotation from Alan Kay, the pioneering computer scientist. We gave the brief of commemorating the BSG's past by asking our experts, patients, nurses, trainees and academics to predict the future of UK gastroenterology and hepatology. The edition begins with a piece from the chief executive of one of the largest patient groups in the UK, envisioning how future healthcare may look, centred as it will be on developing patient choice. The next three pieces directly reflect the change of practice seen in the last 75 years, in as much as they describe the critical role of two historically marginalised groups specialist nurses and trainees. Both groups are now central to the provision of care, and the articles challenge us to plan our future services to maximise their potential. 10.1136/flgastro-2012-100202

There then follows several diseasefocused papers by clinician academics which provide a speculative, challenging and occasionally lighthearted view of the horizon, which we hope will both stimulate thought and potentially lead to changes in one's practice.

It is no coincidence that this publication coincides with the inaugural Digestive Disorders Federation meeting in June 2012, a meeting combining the BSG in its anniversary year with other specialist surgical, hepatology and nutrition societies. As UK gastroenterology and hepatology continues to shine and meet the challenges of service provision in the modern health setting, we are delighted to present this edition of 'Frontline Gastroenterology' as a forward-looking commemoration of a forward-looking Society.

Physiology Unit, University College Hospital, London, UK

Correspondence to Anton V Emmanuel, University College Hospital, Physiology Unit, University College Hospital, 235 Euston Road, Greater London NW1 2BU, UK;

a.emmanuel@ucl.ac.uk

Received 1 May 2012

Accepted 1 May 2012

\section{Competing interests}

Provenance and peer review Commissioned; internally peer reviewed.

\section{References}

1. Hobsbawm E. The age of extremes. UK: Michael Joseph, 1994.

2. Alexander-Williams J, Baron JH. British Society of Gastroenterology 1937-87: an overview. Gut 1987;28 Suppl:53-5. 